\title{
Investigating the Influence of Process Parameters of ZNC EDM on Machinability of A6061/10\% SiC Composite
}

\author{
Balbir Singh, ${ }^{1}$ Jatinder Kumar, ${ }^{1}$ and Sudhir Kumar ${ }^{2}$ \\ ${ }^{1}$ Department of Mechanical Engineering, NIT Kurukshetra, Haryana 136119, India \\ ${ }^{2}$ Department of Mechanical Engineering, NIET, Greater Noida 201306, India
}

Correspondence should be addressed to Balbir Singh; balbir.isst@rediffmail.com

Received 27 May 2013; Accepted 24 July 2013

Academic Editor: J. Paulo Davim

Copyright (c) 2013 Balbir Singh et al. This is an open access article distributed under the Creative Commons Attribution License, which permits unrestricted use, distribution, and reproduction in any medium, provided the original work is properly cited.

\begin{abstract}
A6061/10\% SiC composite has been fabricated by mechanical stir casting process. Fabricated composite has also been characterized through optical microscopy, X-ray diffraction analysis (XRD), scanning electron microscopy analysis (SEM) with energy dispersive $\mathrm{X}$-ray techniques (EDX), and thermogravimetric/differential thermal analysis (TG/DTA). The composite has been experimentally investigated for its machinability using $Z$-axis numerically controlled (ZNC) electrodischarge machining (EDM) process. The effects of the four process parameters, namely, current, gap voltage, pulse-on time, and pulse-off time are investigated on material removal rate (MRR), tool wear rate (TWR), and surface roughness (SR) by varying one parameter at a time approach. Optical microscopy and SEM analysis revealed the uniform distribution of SiC particles in aluminum matrix phase. XRD investigation corroborated the elemental composition of $6061 \mathrm{Al}$ alloy and reinforcement particles. Thermal analysis shows stability of composite upto $650^{\circ} \mathrm{C}$. The machinability characteristics, namely, MRR, TWR, and SR have been interpreted using graphical representations. The study indicates that all the machining parameters affect the machining performance of A6061/10\% SiC composite. Optimum machining performance has been realized at the lower setting of current and pulse-on time and the optimum setting of pulse-off time and gap voltage.
\end{abstract}

\section{Introduction}

Metal matrix composites (MMCs) possess high specific strength and stiffness compared to common structural materials. The most popular type of MMC is aluminium metal matrix composite. Aluminium metal matrix composite consist of matrix phase and reinforcement phase. Matrix phase may be aluminium or aluminium alloy, and reinforcement phase may have graphite, boron carbide, aluminum oxide, silicon carbide, molybdenum, or tungsten in the form of fibers, particles, or whiskers [1]. Applications of aluminum metal matrix composite in various industrial and commercial applications such as aviation, automotive industry, marine, sports, and recreation are expanding exponentially $[2,3]$. Despite excellent mechanical properties, still metal matrix composites are not used widely. The presence of hard reinforcement ( $\mathrm{SiC}$ or $\mathrm{Al}_{2} \mathrm{O}_{3}$ ) in form of particles or fiber leads to excessive tool wear. On account of poor machinability, conventional machining is not adequate for mass production $[4,5]$. Electrodischarge machining is the best alternative to overcome such difficulties in machining of metal matrix composite material. In this paper, an attempt is made to investigate the influence of process parameters of ZNC electrodischarge machining on the machinability of 6061 aluminum alloy reinforced with $10 \% \mathrm{SiC}_{\mathrm{p}}$ composite.

\section{The Literature Review}

Various attempts have been made to analyze or improve the machining performance of EDM along with optimization of machining process parameters for various metal matrix composites materials. Hocheng et al. [6] investigated the machinability of $\mathrm{SiC} / \mathrm{Al}$ composite and compared the EDM machinability of composite with that of steel material. The correlation between the machining parameters and surface roughness is produced on the basis of heat conduction model. Comparable to steel machinability, large current and short pulse-on time are the best combination reported for effective machinability SiC/Al. Gatto and Iuliano [7] evaluated the machinability of $\mathrm{SiC} / 2009 \mathrm{Al}$ alloy (with $15 \%$ whiskers 
TABLE 1: Composition of 6061 aluminum alloy.

\begin{tabular}{ccccccccccc}
\hline Alloy & $\mathrm{Si}$ & $\mathrm{Fe}$ & $\mathrm{Cu}$ & $\mathrm{Mn}$ & $\mathrm{Mg}$ & $\mathrm{Cr}$ & $\mathrm{Zn}$ & $\mathrm{Ti}$ & $\mathrm{Al}$ \\
\hline 6061 & $0.4-0.8$ & 0.7 & $0.15-0.40$ & $0.15-1.2$ & 0.8 & $0.04-0.35$ & 0.25 & 0.15 & Balance \\
\hline
\end{tabular}

and $20 \%$ particles reinforcement) in terms of surface roughness using wire electrodischarge machining process. Increase in reinforcement percentage revealed lesser surface finishing of the machined composite. Yan et al. [8] attempted to improve the machinability of $\mathrm{Al}_{2} \mathrm{O}_{3} / 6061 \mathrm{Al}$ composite using rotary EDM with a dislike electrode. The electrical parameters were reported to be more significant parameters than nonelectrical parameters. Müller and Monaghan [9] investigated the machinability of silicon carbide particle reinforced aluminum alloy matrix composites (AA2618/SiC/20p and A356/SiC/35p) using electrodischarge machining and laser cutting. The presence of $\mathrm{SiC}$ reinforcement decreases MRR when compared to electrodischarge machining with that of $\mathrm{Al}$ alloys without reinforcement. MRR further decreases with the increase in \% concentration of reinforcement. They obtained better results by laser beam machining (LBM) in terms of material removal rate but thermal damage was found to be much less with EDM process. Singh et al. $[10,11]$ studied the machinability of cast aluminum 6061 with $10 \% \mathrm{SiC}_{\mathrm{p}}$ reinforcement using EDM process. The effects of current, pulse-on time, and flushing pressure were studied on MRR, TWR, taper, radial overcut, and roughness. The results were further optimized. Cichosz et al. explored the machinability of aluminium reinforced with ceramic $\mathrm{Al}_{2} \mathrm{O}_{3}$ fibers of the Saffil type and presented the influence of various machining parameters on the quality of surface layer produced with machining. Habib [12] optimized the process parameters in EDM through response surface methodology approach while working with machining of SiC/Al using ZNC EDM. The results with similar trends and better precision were obtained.

In view of above the discussion, there are various challenges in the machining of metal matrix composite. Continuous research is being focused more on various approaches to improve the machinability of metal matrix composite. On account of their vast industrial applications, there is need to further explore machinability of $\mathrm{Al}$ alloy reinforced with $\mathrm{SiC}$ particles composites. Present paper explored the possibility of ZNC EDM machining of 6061 aluminum alloy reinforced with 10\% SiC composite. A6061/10\% SiC composite is fabricated by mechanical stir casting process. Fabricated composite is characterized by XRD, TG/DTA, SEM, and optical microscopy study. Various EDM process parameters such as pulse current, gap voltage, pulse-on time, and pulse-off time were varied to investigate their effects on the machining of aluminum metal matrix composite.

\section{Experimental Procedure}

3.1. Material Selection. Aluminum 6061 alloy is selected. Aluminium alloy $6 \mathrm{xxx}$ series, specially 6061, is a general purpose alloy. It is used extensibly in civil aviation and automobile sector. This is the least expensive and most versatile

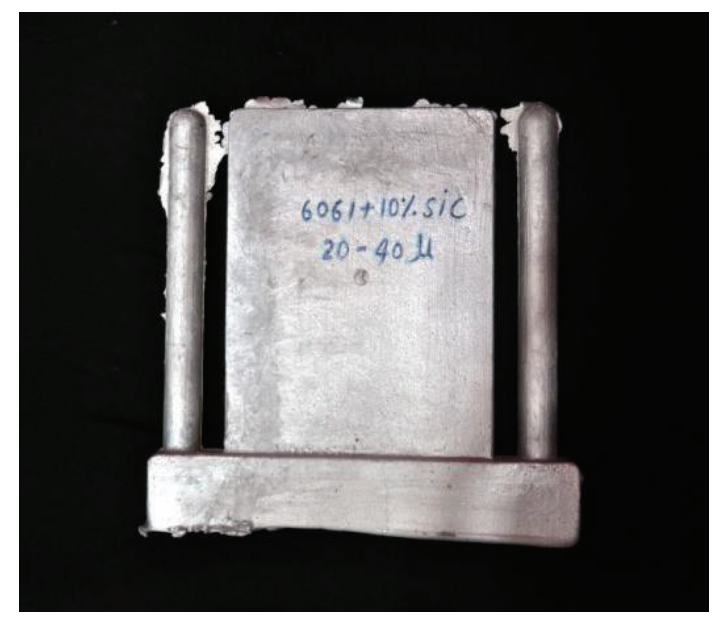

FIGURE 1: $\mathrm{Al} / \mathrm{SiC}_{\mathrm{p}}$ cast from stir casting process.

of the heat treatable aluminum alloys. It has a very good corrosion resistance, finishability, and excellent weldability. The composition of 6061 aluminium alloy is shown in Table 1. $\mathrm{SiC}$ is selected as reinforcement material.

The composite is fabricated by stir casting process. The aluminium alloy was melted in a graphite crucible under controlled argon environment. A small amount of magnesium, less than $0.5 \%$ of total weight, was added to improve wettability between molten metal and reinforcement particles. A furnace temperature was maintained at $750^{\circ} \mathrm{C}$ for 30 minute till complete melting of aluminium alloy was achieved. Vortex was created by mechanical stirring at a speed of $600 \mathrm{rpm}$ using graphite impeller. Specific amount of $\mathrm{SiC}$ particles equal to 10 vol. $\%$ was preheated to $750^{\circ} \mathrm{C}$ before pouring into molten metal crucible. Stirring was continued to facilitate uniform distribution of reinforcement particles into the molten metal. The composite melt was further stirred for 5 minutes and casted into permanent mould through bottom pour process. The cast obtained by casting process is presented in Figure 1.

\section{Characterization of $\mathbf{A 6 0 6 1 / 1 0 \%}$ SiC Composite}

4.1. Microstructure. The microstructural characterization studies using metallurgical microscope were conducted on composite samples reinforced with $\mathrm{SiC}_{\mathrm{p}}$ content having 20$40 \mu \mathrm{m}$ size. The composite sample was metallographically polished prior to examination as per ASTM E3 standard. Sample was examined at $\times 400$ magnification. The microstructure of the as-cast composite revealed that the agglomerates of $\mathrm{SiC}$ particles are uniformly distributed in the matrix which are shown in Figure 2. 


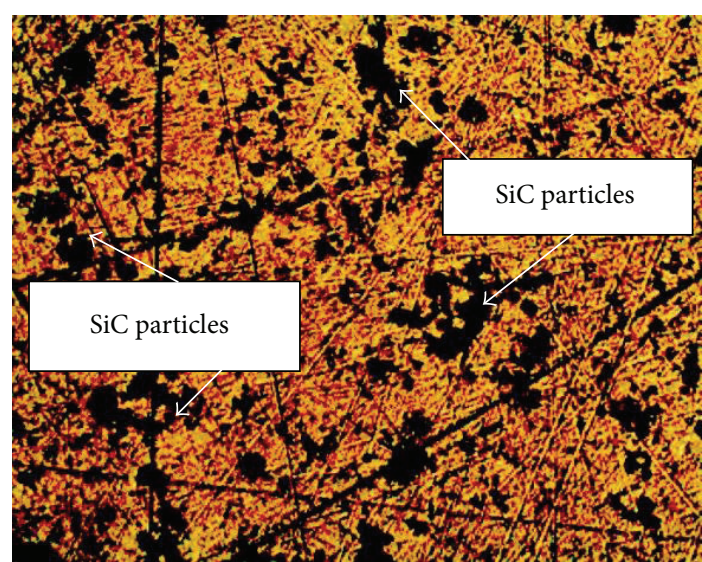

FIgURE 2: Optical microstructure with $20-40 \mu \mathrm{m} \mathrm{SiC}$ p at $400 \mathrm{x}$.

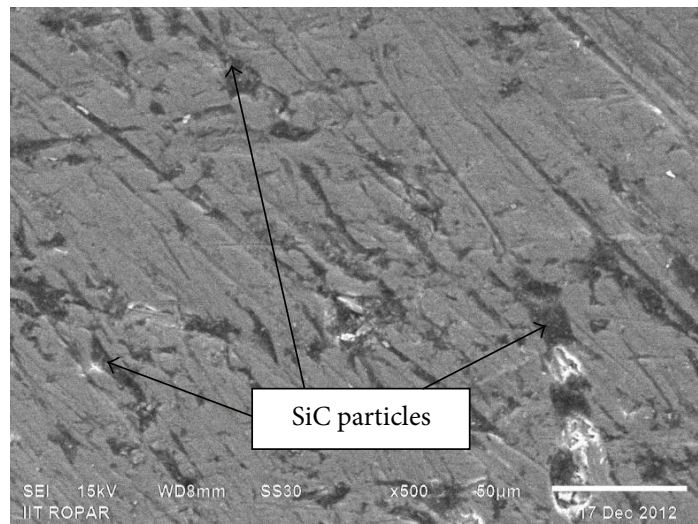

FIGURE 3: SEM micrograph of $6061 \mathrm{Al} / \mathrm{SiC}_{\mathrm{p}}$ before machining.

4.2. SEM and EDX Analysis. The constitutional assessments of $\mathrm{A} 6061 / 10 \% \mathrm{SiC}$ composite are made by energy dispersive $\mathrm{X}$-ray (EDX) in scanning electron microscope testing. Figure 3 shows the SEM micrograph of composite workpiece before electrodischarge machining. The clustering of $\mathrm{SiC}$ particles is distributed over the entire region resulting in $\mathrm{SiC}$ rich particle region. These agglomerations consist of larger particles surrounded by smaller particles in aluminum phase solidification as shown in SEM microscopic structure. The EDX spectrum in Figure 4 shows major portion of aluminium and silicon in carbide form and rest a very small percentage of other constituents present in recast layer formed on machined surface.

4.3. XRD Analysis. X-ray diffraction analysis is carried out to identify the unwanted material present in the composite material. Figure 5 shows the XRD patterns of aluminium and silicon carbide at 2-Theta scale. No other unwanted elements are present which further corroborate the mentioned results of compositional analysis.

4.4. TG/DTG/DTA Analysis. Thermal analysis is performed to investigate the physical properties of material under controlled temperature programme. TG/DTA analysis was carried out as per American Society for Testing and Materials

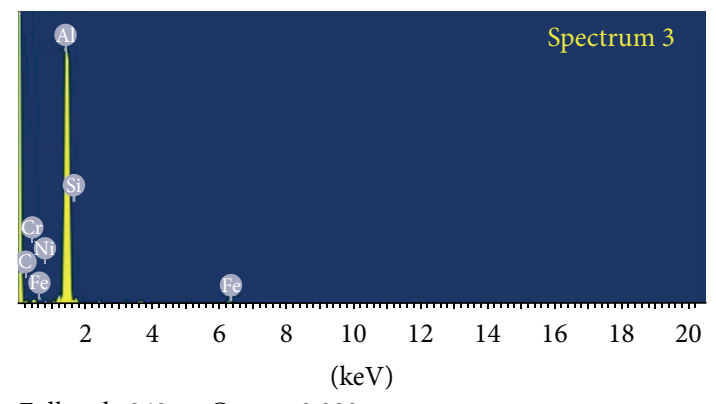

Full scale 243 cts Cursor: 0.000

FIgURE 4: EDX spectrum of $6061 \mathrm{Al} / \mathrm{SiC}_{\mathrm{p}}$ before machining.

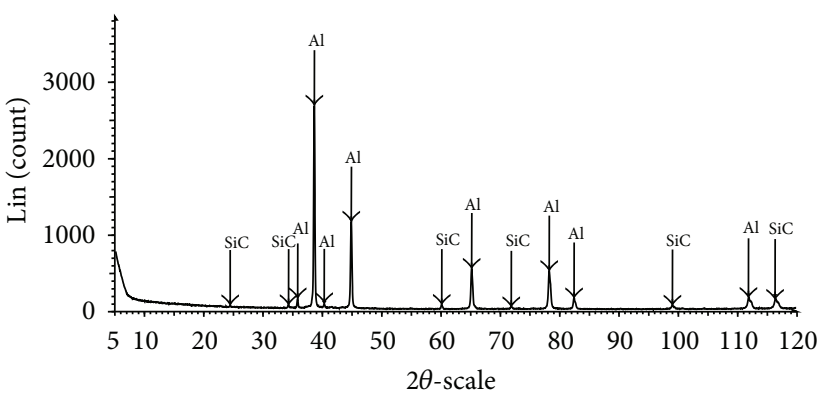

FIGURE 5: X-ray diffraction patterns of $6061 \mathrm{Al} / \mathrm{SiC}$ powdered composite.

Standard (ASTM E2550-11) on a sample of 6061 aluminum alloy reinforced with $10 \% \mathrm{SiC}$ particles in a powder form with a weight of $10.915 \mathrm{mg}$ in EXSTAR TG/DTA 6300 thermal analyzer. The sample was heated in the atmosphere of nitrogen with $99.99 \%$ purity which was supplied at rate of $200 \mathrm{~mL} / \mathrm{min}$, and temperature was increased from ambient temperature to $1500^{\circ} \mathrm{C}$ at a rate of $20^{\circ} \mathrm{C} / \mathrm{min}$. Thermogravimetric (TG)/derivative thermogravimetry (DTG) analysis determines thermal decomposition and changes in weight of sample in relation to change in temperature. TG curve in Figure 6 shows that sample is stable upto $800^{\circ} \mathrm{C}$ and thereafter decomposition start, reactant mass percent is changing from 101.2 to 126.0 with the change of temperature from $1000^{\circ} \mathrm{C}$ to $1200^{\circ} \mathrm{C}$. After $1000^{\circ} \mathrm{C}$, decomposition starts rapidly. DTG curve shows that the mass of composite sample is constant upto $900^{\circ} \mathrm{C}$ and thereafter starts losing. Hence, it shows that the decomposition of composite starts only after $900^{\circ} \mathrm{C}$.

Differential thermal analysis (DTA) is a calorimetric technique. It works on the principle of difference in temperature between a sample and reference material when they are subjected to a controlled temperature program. DTA Test records the temperature and heat flow associated with thermal transitions in materials [13]. DTA curve from Figure 6 shows a very small endothermic peak at $653^{\circ} \mathrm{C}$ which is showing the melting of $\mathrm{Al}$ alloy and $\mathrm{Mg}$ without changing the mass of sample. At $1099^{\circ} \mathrm{C}$, it shows reaction of nitrogen with aluminum producing AlN as shown by exothermic reaction peak in DTA curve. Thermal analysis shows the overall stability of composite upto $650^{\circ} \mathrm{C}$. 


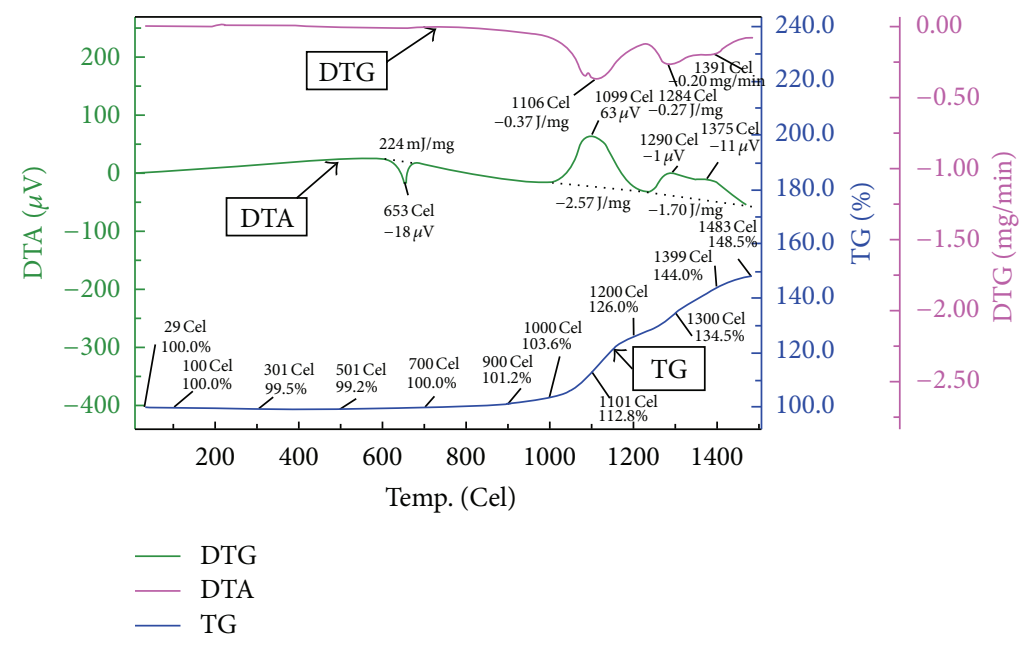

Figure 6: TG, DTG, and DTA graph of A6061/10\% SiC composite.

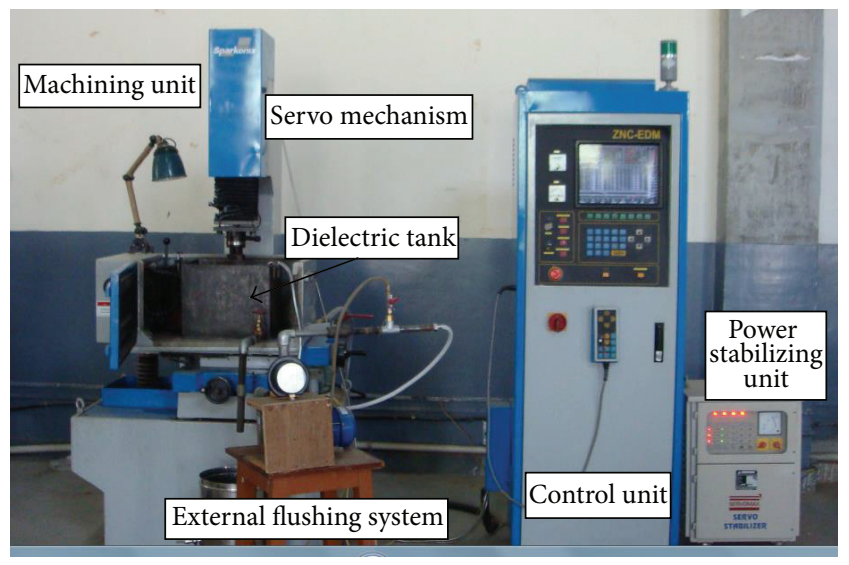

FigURE 7: ZNC EDM setup for experiment.

A fabricated A6061/10\% SiC composite is characterized for microstructure, elemental compositional, and thermal analyses. SEM and optical microstructure results show uniform distribution of $\mathrm{SiC}$ reinforcement in aluminum phase. XRD and EDX analyses reveal elemental composition of 6061 $\mathrm{Al}$ alloy along with the presence of $\mathrm{SiC}$ particles reinforcement. Thermal analysis declares the stability of fabricated composite upto $650^{\circ} \mathrm{C}$ for specific applications.

\section{ZNC Electrical Discharge Machine}

Experiments have been performed on ZNC electrical discharge machine (model S-50) made by Sparkonix, India. Various machining characteristics such as MRR, TWR, and SR are investigated at different settings of current, voltage, pulse-on time, and pulse-off time. Special circulation system was fabricated and used for the flushing of machining area as shown in Figure 7 of ZNC EDM set up.

The experiments have been performed using electrode of electrolytic copper (density $8.95 \mathrm{~g} / \mathrm{cm}^{3}$ ) having a diameter of $12.5 \mathrm{~mm}$ and $150 \mathrm{~mm}$ height with positive polarity. During
TABLE 2: Machining process parameters and their levels.

\begin{tabular}{llc}
\hline Sl. no. & Machining parameters & Levels \\
\hline$(1)$ & Current $($ Amp $)$ & $1,3,6,9,15,30$ and 45 \\
$(2)$ & Gap voltage $(V)$ & $30,40,50,60,70,100$ and 120 \\
$(3)$ & Pulse-on time, $T_{\text {on }}(\mu \mathrm{s})$ & $4,8,15,90,200,500$ and 900 \\
$(4)$ & Pulse-off time $T_{\text {off }}(\mu \mathrm{s})$ & $4,8,15,90,200,500$ and 900 \\
\hline
\end{tabular}

experimentation, electrode area was kept constant throughout all experiments. Commercial grade kerosene was used as the dielectric fluid with side flushing, keeping constant pressure at $0.5 \mathrm{Kgf} / \mathrm{cm}^{2}$ during the entire machining process.

The experiments have been performed at different levels of peak current, pulse-on time, voltage, and pulse-off time as mentioned in Table 2 by varying one parameter approach. The machining was carried out for a fixed time interval of 30 mins repeating each experiment two times. All the experiments are performed keeping electrode positive and workpiece negative polarity. The machined workpiece is sh own in Figure 8. The MRR and TWR were evaluated for each cutting condition by measuring average weight before and after each experiment using precision measuring balance with $0.01 \mathrm{mg}$ accuracy. The surface roughness ( $\mathrm{Ra}$ ) was measured taking the average of three readings using surface roughness SRT 6120 tester taking cutoff length of $0.8 \mathrm{~mm}$.

\section{Results and Discussion}

6.1. Material Removal Rate. The experimental results obtained are plotted for MRR, TWR, and SR at various settings of process parameters as shown in Figure 9 to Figure 20. MRR as shown in Figure 9 has been found to be increased with the increase in current, keeping other parameters constant. MRR is lowest at current of $1 \mathrm{Amp}$ and maximum at $45 \mathrm{Amp}$. This might be due to higher energy input at elevated values of current. The MRR is also found to increase nonlinearly with the increase in pulse-on time (keeping current, pulse-off time, and gap voltage constant). As observed from Figure 10, 


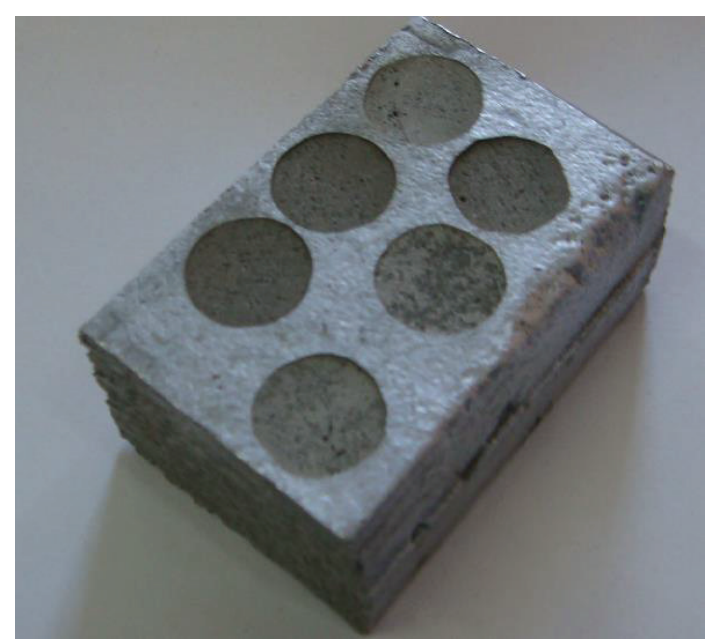

FIGURE 8: Electrodischarge machined workpiece.

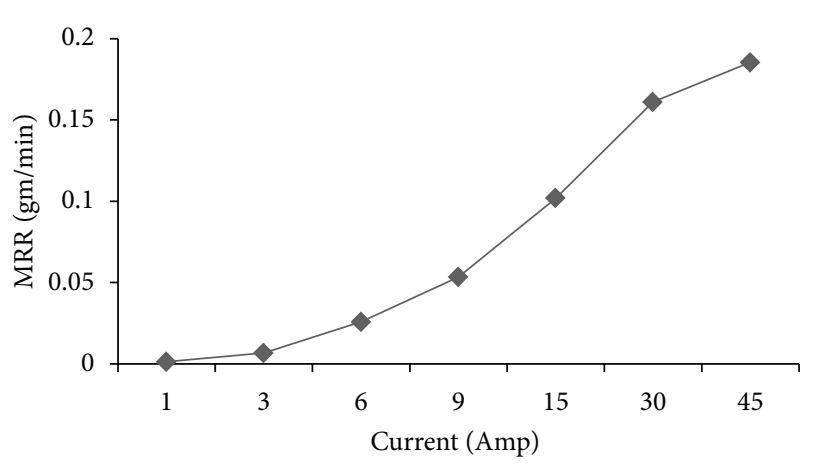

FIGURE 9: Influence of current on MRR at constant voltage $60 \mathrm{~V}$, pulse-on time $90 \mu \mathrm{s}$, and pulse-off time $90 \mu \mathrm{s}$.

MRR increases nonsignificantly upto pulse duration of $15 \mu \mathrm{s}$ on account of insufficient discharging time for melting and vaporization. Further, it increases linearly upto $200 \mu$ s and then follows decreasing trend which might be attributed to an expansion of the plasma channel, thereby decreasing the energy density in the machining process. The optimum pulse-on time must be obtained to yield a better machining performance.

Figure 11 shows the influence of pulse-off time on MRR when machining was performed at peak current 9 Amp, gap voltage 60 volt, and pulse-on time $90 \mu \mathrm{s}$. MRR reported to be optimum at $90 \mu \mathrm{s}$. Too short pulse-off time leads to insufficient time for cooling and debris removal with the flow of the dielectric fluid. Due to shorter pulse-off time, the dielectric fluid does not get sufficient time to deionize before the start of the next discharge cycle. This causes the next spark to be unstable and slows down the cutting process. In general, the pulse-off time should be greater than the deionization time to prevent continued sparking at one point. Optimum setting of pulse-on time and pulse-off time is desired to get best speed and stability of machining process. In starting of spark cycle, the gap voltage increases until an ionization path is built through dielectric. As the current starts flowing,

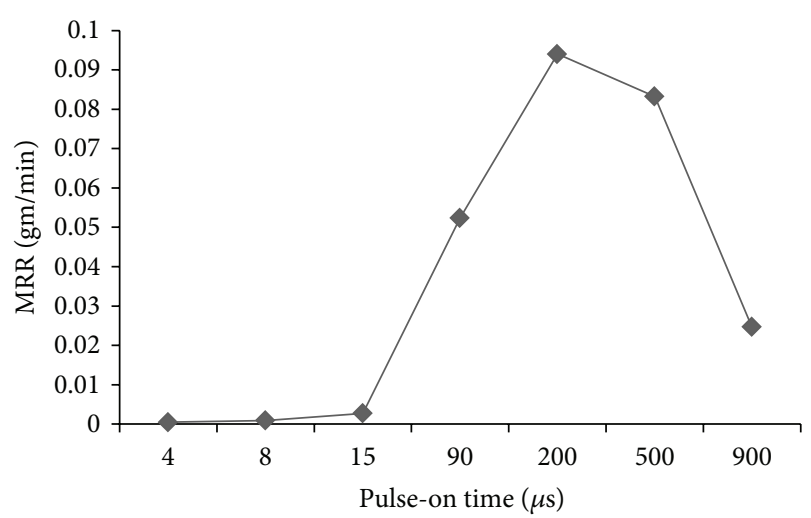

Figure 10: Influence of pulse-on time on MRR at constant current 9 Amp, gap voltage $60 \mathrm{~V}$, and pulse-off time $90 \mu \mathrm{s}$.

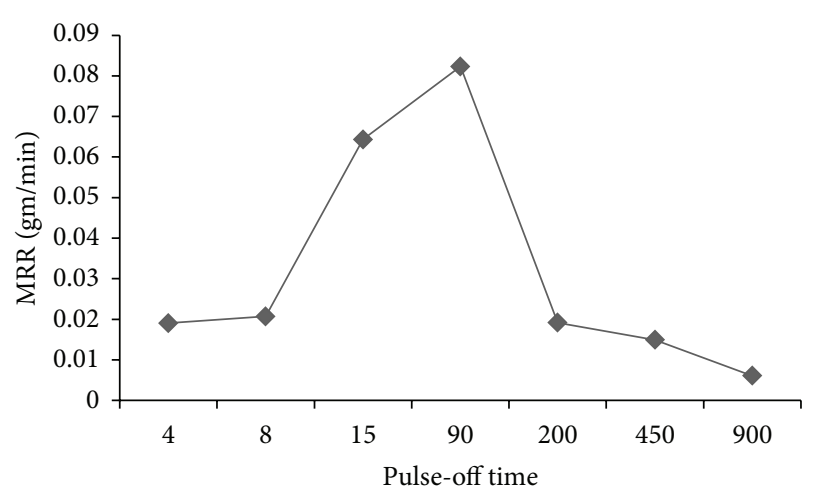

FIGURE 11: Influence of pulse-off time on MRR at constant current 9 Amp, gap voltage $60 \mathrm{~V}$, and pulse-on time $90 \mu \mathrm{s}$.

voltage drops and stabilizes at the working gap level. From previous research, it is reported that by keeping all other factors constant, increase in gap voltage increases the energy per spark and hence increases MRR. However, from Figure 12, MRR tends to decrease at higher setting of gap voltage. This downward trend may be attributed to the increase in the pulse duration to build up the higher gap voltage across the gap which results in decrease of the sparking frequency and the net outcome is the fall in MRR.

6.2. Tool Wear Rate. Figure 13 presents tool wear rate versus current at constant setting of voltage, pulse-on time, and pulse-off time. TWR has been observed to increase with the increase in current value. It has also been found that variation of TWR is not uniform. Initially, the wear is very small due to low setting of input current and thereafter increases rapidly and is maximum at $45 \mathrm{Amp}$ current. The variation of TWR also shows increasing trend with the increase of pulse-on time as seen in Figure 14. This phenomenon may be attributed to the transfer of more energy during discharging process; however, variation is more significant with current parameter than pulse-on time for a given range of settings.

Figure 15 evaluates the effect of pulse-off time on TWR at constant setting of current, gap voltage, and pulse-on time. TWR decreases with the increase in pulse-off time. 


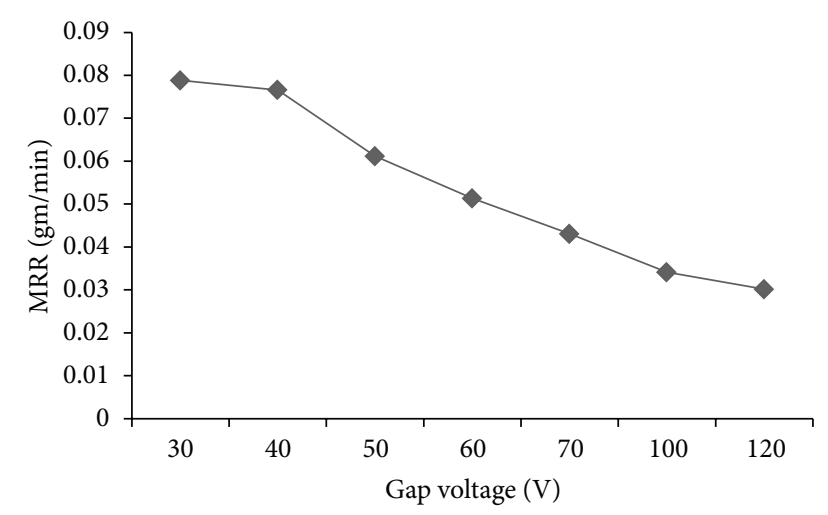

FIGURE 12: Influence of gap voltage on MRR at constant current 9 Amp, pulse-on time $90 \mu \mathrm{s}$, and pulse-off time $90 \mu \mathrm{s}$.

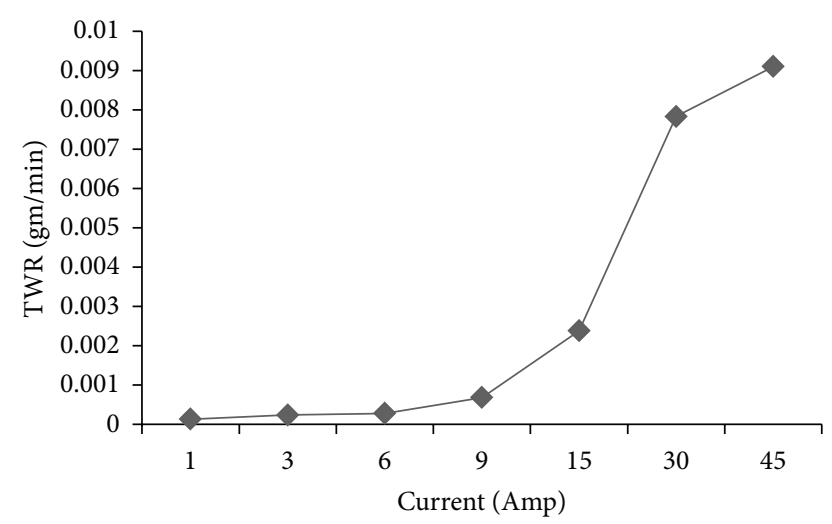

FIGURE 13: Influence of current on TWR at constant gap voltage $60 \mathrm{~V}$, pulse-on time $90 \mu \mathrm{s}$, and pulse-off time $90 \mu \mathrm{s}$.

Too short pulse-off time does not produce stable discharge, hence no machining of workpiece. The pulse-off time is the time required for the deionization of the dielectric fluid at the end of discharge duration, hence facilitates stabilizing the machining process. Increase in pulse interval may provide sufficient time for the cooling of electrode between two discharges resulting in lower TWR. The effect of gap voltage on TWR is almost negligible as shown in Figure 16 when comparing with other process parameters. Best results for TWR have been obtained at gap voltage setting in the range of $50 \mathrm{~V}$ to $70 \mathrm{~V}$.

6.3. Surface Roughness. Surface roughness (Ra) obtained on electrodischarge machining of $\mathrm{A} 6061 / 10 \% \mathrm{SiC}$ composite by varying the settings of current value at constant pulse-on time, pulse-off time, and gap voltage is shown in Figure 17. Result show increasing trend of roughness with current. This is mainly due to more discharge energy released with the increase of current, making a bigger crater at the site of discharge and thus rougher surface is produced. Similar trends of surface roughness are obtained with the increase of pulse duration as shown in Figure 18. The discharge energy increases with increasing pulse-on time, resulting in bigger melt cavities and rougher surface of machined composite

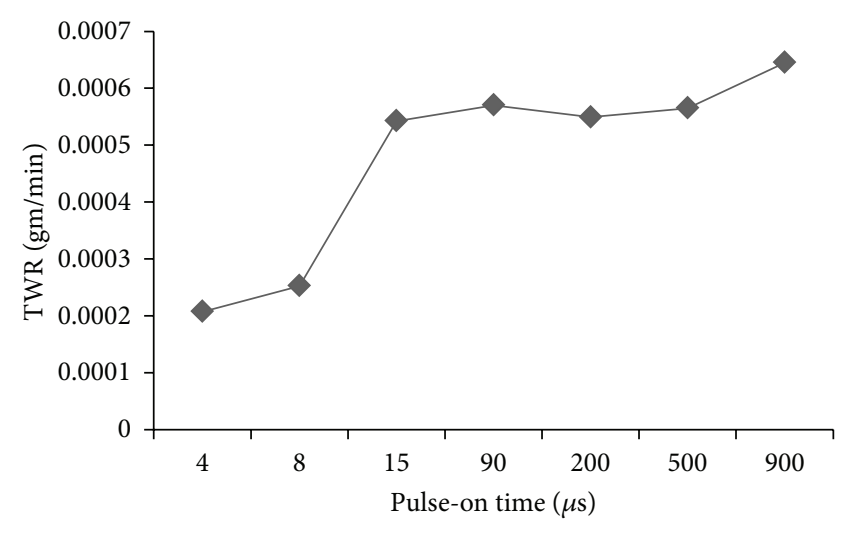

FIgURE 14: Influence of pulse-on time on TWR at constant current 9 Amp, gap voltage $60 \mathrm{~V}$, and pulse-off time $90 \mu \mathrm{s}$.

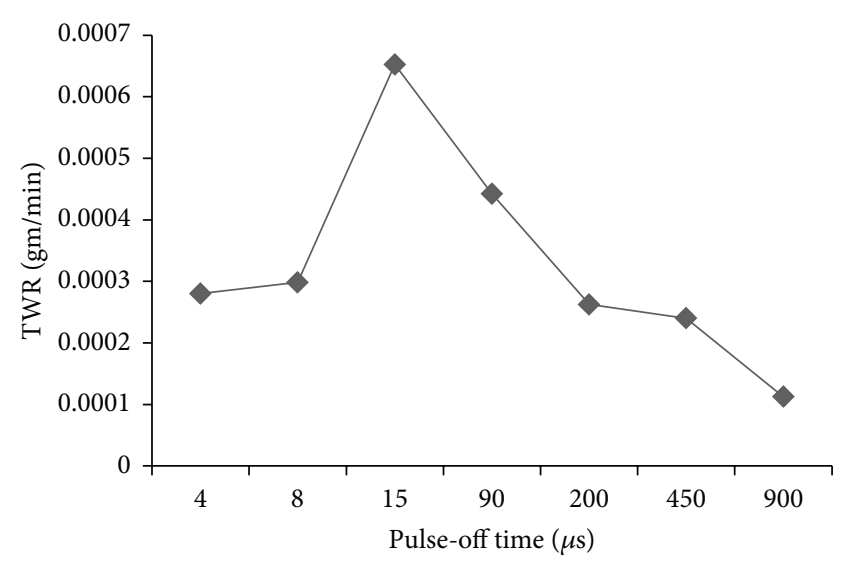

FIGURE 15: Influence of pulse-off time on TWR at constant current 9 Amp, gap voltage $60 \mathrm{~V}$, and pulse-on time $90 \mu \mathrm{s}$.

material. However, at low level of current and pulse-on time, better results of surface finish are obtained.

Surface roughness variation with respect to pulse-off time is not significant compared with other machining parameters as shown in Figure 19. The too short pulse-off time is not sufficient in clearing debris from sparking gap, hence not suitable for large current setting. The machining of composite material with copper electrode has an optimum pulse-off time of $90 \mu \mathrm{s}$, at which minimum surface roughness and highest material removal rate are obtained. Keeping all other parameters constant, an increase in the gap voltage will result in increased pulse duration and decreased discharge frequency, which may improve the surface finishing initially, as long as the effect of increased pulse duration is dominated by the fall in discharging frequency. After crossing a threshold value of $50 \mathrm{~V}$, the roughness starts increasing at a rapid pace due to formation of larger, deeper craters because of the increased pulse duration. Best surface finish results were observed at gap voltage of $50 \mathrm{~V}$ in this experiment. Figure 21 shows poor surface finish due to the presence of craters and $\mathrm{SiC}$ reinforcement in recast layer deposited on the machined surface of composite material. The machining at $9 \mathrm{Amp}$, $60 \mathrm{~V}, 90 \mu$ s pulse-on time, and $90 \mu$ s pulse-off time generated 


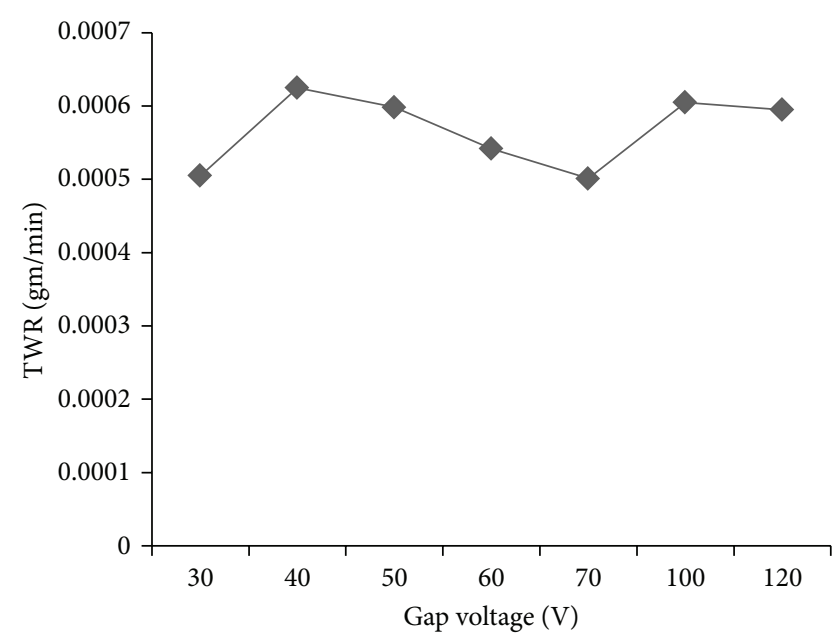

FIGURE 16: Influence of gap voltage on TWR at constant current 9 Amp, pulse-on time $90 \mu \mathrm{s}$, and pulse-off time $90 \mu \mathrm{s}$.

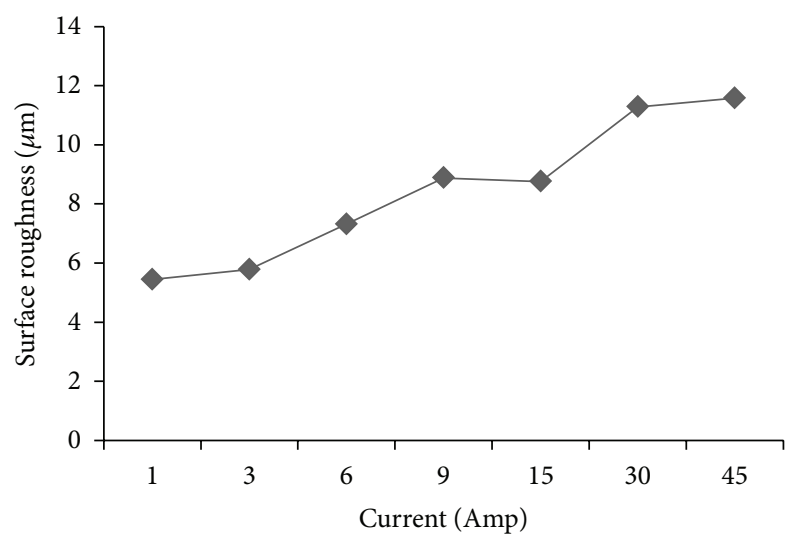

FIGURE 17: Influence of current on SR at constant gap voltage $60 \mathrm{~V}$, pulse-on time $90 \mu \mathrm{s}$, and pulse-off time $90 \mu \mathrm{s}$.

craters with varied size which are responsible for poor surface finish. Figure 22 shows the presence of various compositional elements which are present in the composition of $6061 \mathrm{Al} / \mathrm{SiC}$ composite as mentioned in Table 1. Under influence of high thermal energy generated during discharge, the dielectric fluid (kerosene) decomposes and transfer of carbon to the machined surface occurs, forming recast layer. The presence of carbon is depicted in EDX results.

\section{Conclusions}

The following conclusion may be drawn from the experimental study.

(1) Optical microscopy and SEM analysis shows clusters of $\mathrm{SiC}$ reinforcement throughout the composite structure. EDX results confirm the presence of compositional elements of $6061 \mathrm{Al}$ alloys along with reinforcement particles of silicon carbide.

(2) A6061/10\% SiC composite is thermally stable upto $650^{\circ} \mathrm{C}$ as interpreted from TG, DTA, and DTG tests.

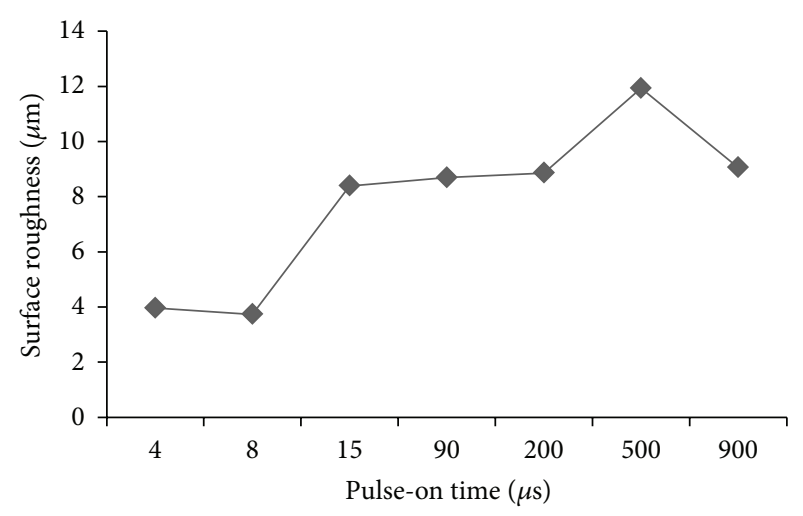

FIGURE 18: Influence of pulse-on time on SR at constant current 9 Amp, gap voltage 60, and pulse-off time $90 \mu$ s.

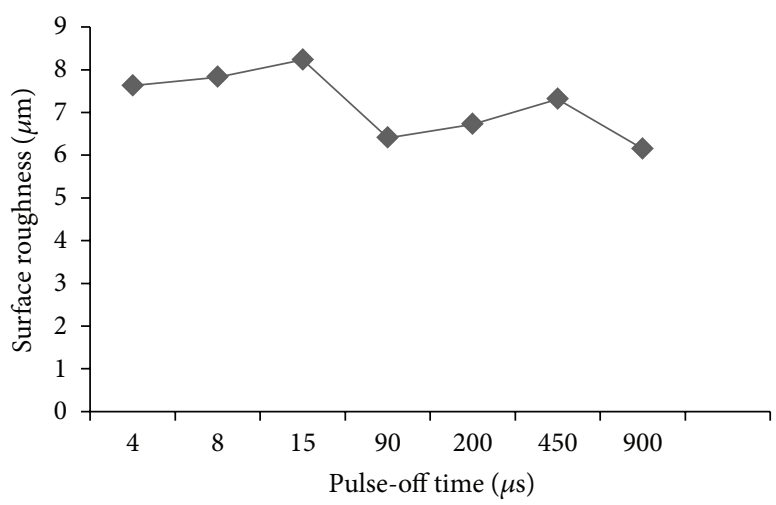

FIGURE 19: Influence of pulse-off time on SR at constant current 9 Amp, gap voltage $60 \mathrm{~V}$, and pulse-on time $90 \mu \mathrm{s}$.

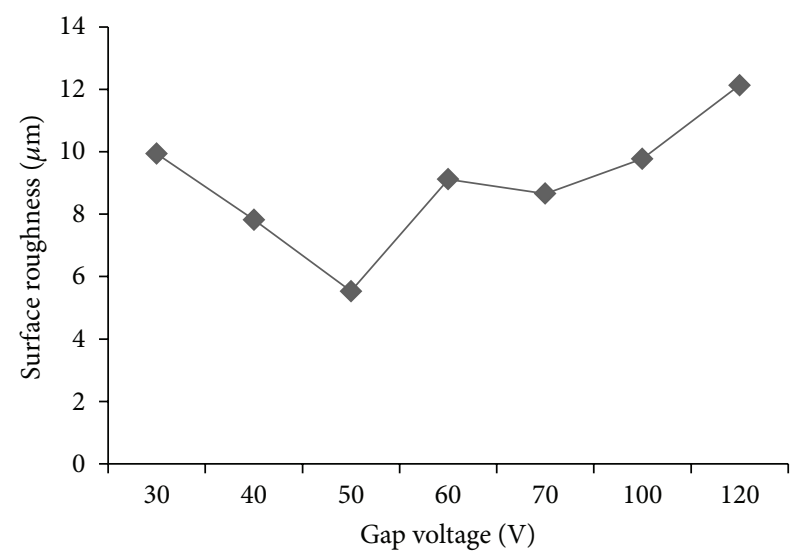

FIGURE 20: Influence of gap voltage on SR constant current 9 Amp, pulse-on time $90 \mu \mathrm{s}$, and pulse-off time $90 \mu \mathrm{s}$.

(3) The machining characteristic MRR achieved best results at the maximum setting of current. Best surface finish and lowest tool wear rate may be obtained at low setting of current.

(4) With an increase of pulse-on time, all the three dependent characteristics, namely, MRR, TWR, and SR, 


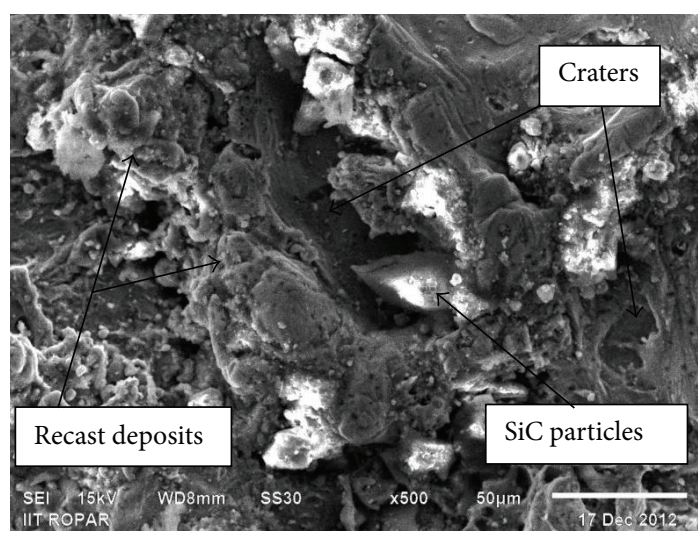

FIGURE 21: SEM photograph of machined surface (9 Amp, $60 \mathrm{~V}, \mathrm{~T}_{\mathrm{on}^{-}}{ }^{-}$ $90 \mu \mathrm{s}$, and $\left.T_{\text {off }}-90 \mu \mathrm{s}\right)$.

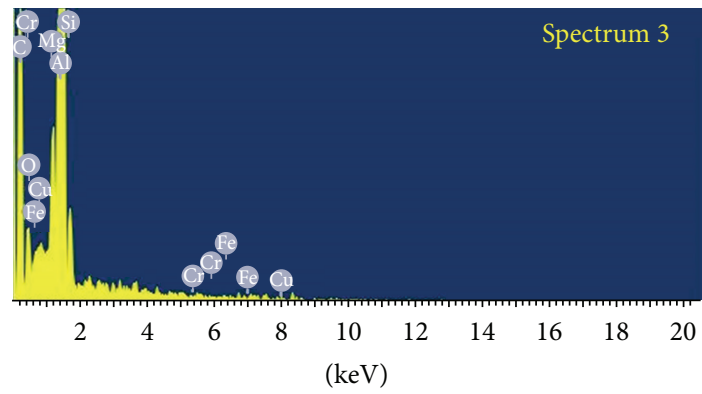

Full scale 243 cts Cursor: 0.000

Figure 22: EDX of machined surface ( $9 \mathrm{Amp}, 60 \mathrm{~V}, T_{\text {on }}-90 \mu \mathrm{s}$, and $\left.T_{\text {off }}-90 \mu \mathrm{s}\right)$.

increase. However, optimum results were obtained at lower setting of pulse duration and pulse interval from 90 to $200 \mu \mathrm{s}$.

(5) As the spark gap between electrode and workpiece is decided by the set gap voltage, the surface roughness increases with the increase in gap voltage. Optimum results for surface quality were obtained at gap voltage setting of $50 \mathrm{~V}$. However, variation of gap voltage did not produce significant variation in TWR. Higher setting of voltage produced counter productive results for material removal rate and showed downward trend for MRR.

\section{Acknowledgments}

The authors would like to acknowledge the Institute Instrumentation Centre, IIT Roorkee, India, and the Central Research Facility, IIT Ropar, India, for their support in using testing facilities for carrying out research work.

\section{References}

[1] M. K. Surappa, "Aluminium matrix composites: challenges and opportunities," Sadhana, vol. 28, no. 1-2, pp. 319-334, 2003.

[2] J. U. Ejiofor and R. G. Reddy, "Developments in the processing and properties of particulate Al-Si composites," JOM, vol. 49, no. 11, pp. 31-37, 1997.
[3] V. M. Kevorkijan, "Aluminum composites for automotive applications: a global perspective," JOM, vol. 51, no. 11, pp. 54-58, 1999.

[4] M. El-Gallab and M. Sklad, "Machining of $\mathrm{Al} / \mathrm{SiC}$ particulate metal-matrix composites-part I: tool performance," Journal of Materials Processing Technology, vol. 83, no. 1-3, pp. 151-158, 1998.

[5] A. Manna and B. Bhattacharyya, "A study on different tooling systems during machining of $\mathrm{Al} / \mathrm{SiC}-\mathrm{MMC}$," Journal of Materials Processing Technology, vol. 123, no. 3, pp. 476-482, 2002.

[6] H. Hocheng, W. T. Lei, and H. S. Hsu, "Preliminary study of material removal in electrical-discharge machining of SiC/Al," Journal of Materials Processing Technology, vol. 63, no. 1-3, pp. 813-818, 1997.

[7] A. Gatto and L. Iuliano, "Cutting mechanisms and surface features of WED machined metal matrix composites," Journal of Materials Processing Technology, vol. 65, no. 1-3, pp. 209-214, 1997.

[8] B. H. Yan, C. C. Wang, W. D. Liu, and F. Y. Huang, "Machining characteristics of $\mathrm{Al}_{2} \mathrm{O}_{3} / 6061 \mathrm{Al}$ composite using rotary EDM with a disklike electrode," International Journal of Advanced Manufacturing Technology, vol. 16, no. 5, pp. 322-333, 2000.

[9] F. Müller and J. Monaghan, "Non-conventional machining of particle reinforced metal matrix composites," Journal of Materials Processing Technology, vol. 118, no. 1-3, pp. 278-285, 2001.

[10] P. N. Singh, K. Raghukandan, and B. C. Pai, "Optimization by Grey relational analysis of EDM parameters on machining Al10\%SiCP composites," Journal of Materials Processing Technology, vol. 155-156, no. 1-3, pp. 1658-1661, 2004.

[11] P. N. Singh, K. Raghukandan, M. Rathinasabapathi, and B. C. Pai, "Electric discharge machining of $\mathrm{Al}-10 \% \mathrm{SiCP}$ as-cast metal matrix composites," Journal of Materials Processing Technology, vol. 155-156, no. 1-3, pp. 1653-1657, 2004.

[12] S. S. Habib, "Study of the parameters in electrical discharge machining through response surface methodology approach," Applied Mathematical Modelling, vol. 33, no. 12, pp. 4397-4407, 2009.

[13] R. P. W. Scott, Book V-Thermal Analysis, Open Publication Structure e-Book, http://physicalchemistryresources.com/ Book5_sections/pc_ec_titleandcontents_10132009.htm. 

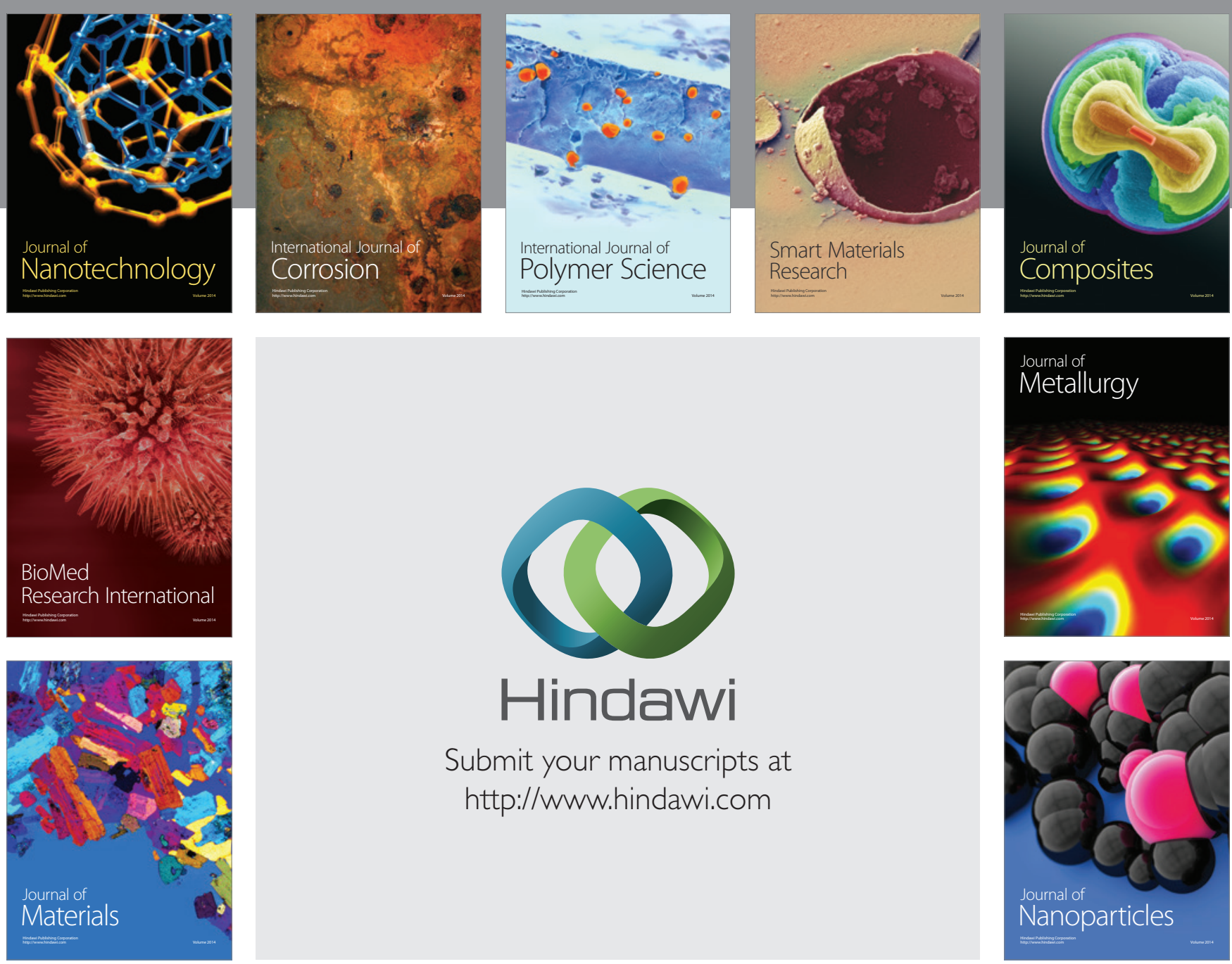

Submit your manuscripts at http://www.hindawi.com
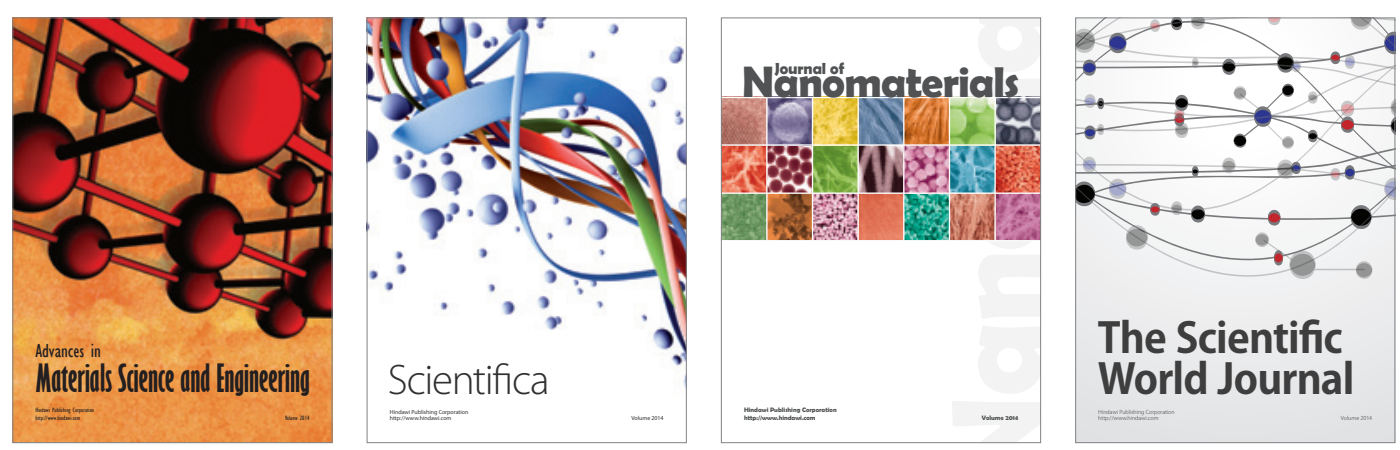

\section{The Scientific World Journal}
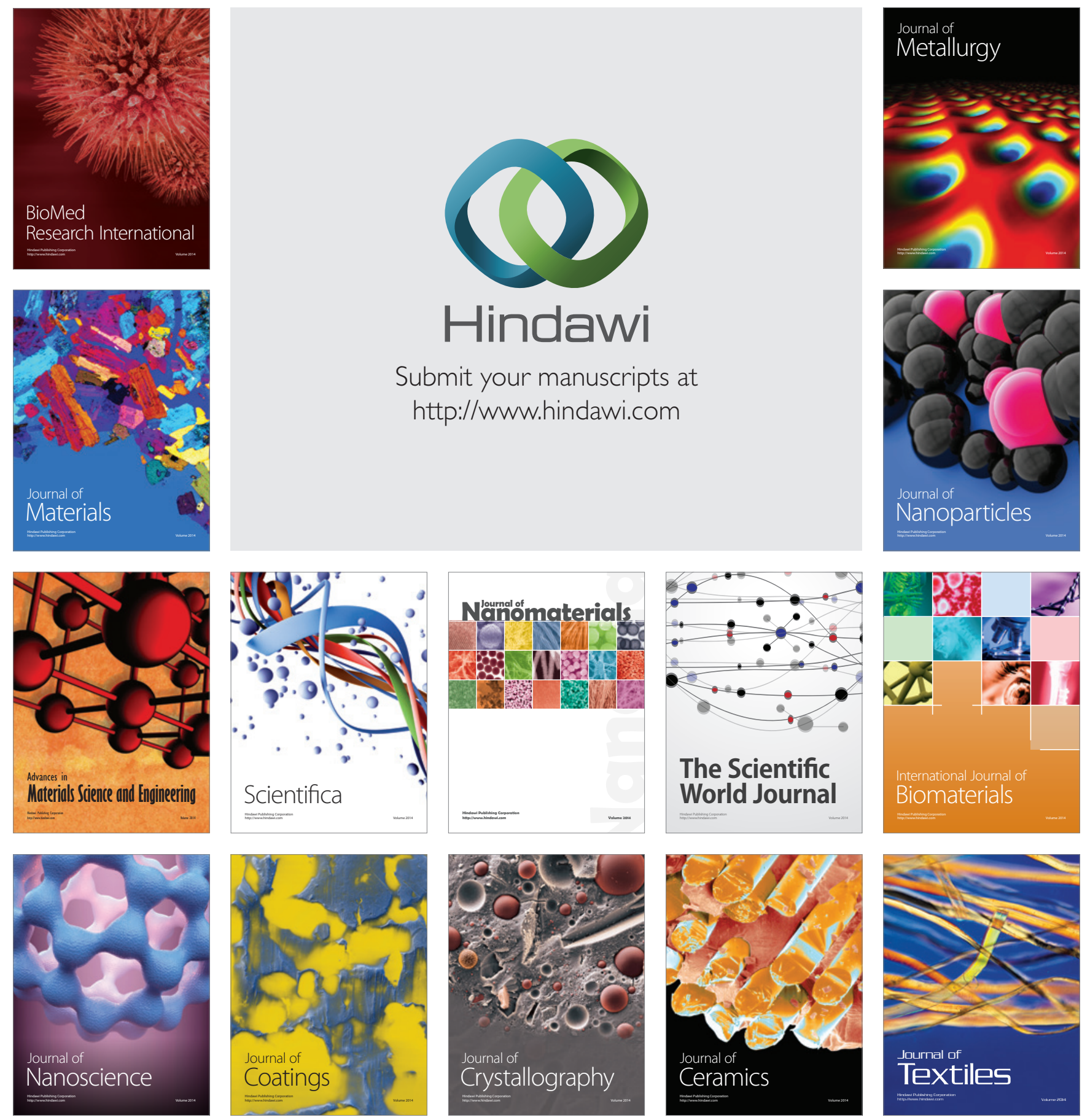